\title{
Direct and Dissociative Ionization Cross Section of Oxygen Molecule from Threshold to $10 \mathrm{KeV}$
}

\author{
Ravinder Sharma, S.P.Sharma
}

\begin{abstract}
Due to abundant applications of ionization in various fields of applied sciences, it's desirable to calculate absolute ionization cross sections of various atoms or molecules. In this literature, we have calculated the absolute direct and dissociative ionization cross sections of the oxygen molecule from threshold energy to 10,000 eV by using revisited Jain-Khare semi-empirical approach.

In this literature, the total direct and absolute ionization cross section data have compared with easily available experimental and/or theoretical data. The present results give a better account for the ionization cross sections up to higher incident electron energies.
\end{abstract}

Keywords: Direct and dissociative ionization, Electron impact ionization, Ionization cross section.

\section{INTRODUCTION}

Oxygen is an interesting molecule to study. However, many work have been done on the $\mathrm{O}_{2}$ molecule. As the wide significant properties of the $\mathrm{O}_{2}$ molecule, we have determined the direct and dissociative ionization cross sections of the oxygen molecule. There are many applications in the field of plasma processes; vacuum technology, ionosphere, gas discharges, planetary atmospheres and others [1], [2].

Since the 1930s, many experimental and theoretical ionization cross sections have been carried out for the $\mathrm{O}_{2}$ molecule and the techniques are improved from time to time. James A. R. Samson [3], Krishan Kumar and Srivastava [4] and B.VanZyl [5] studied the ionization cross sections of the $\mathrm{O}_{2}$ molecule experimentally. And the same work had been analyzed by Straub and co-worker theoretically and determines the cross section up to $1000 \mathrm{eV}$ [6].

Donald Rapp [1], S. P. Khare [7], D. Margreiter [8], H. Deutsch [9], Ashok Jain [10], VandanaSaksena [11], K. N. Joshipura [2] used the different theoretical methods and gave the total ionization cross sections for the $\mathrm{O}_{2}$ and other molecules. Recently, Stefan E.Huber et al. [12] derived the partial and total ionization cross sections for the $\mathrm{O}_{2}$ and other fusion -relevant diatomic molecules from threshold to $10 \mathrm{KeV}$ using the binary -encounter-Bethe and the DeutschMark formalisms. So, there are several cross sections for the $\mathrm{O}_{2}$ molecule, only a few are discussed here. There are various theoretical formalisms to determine the ionization cross sections of molecules[8], [14]. For better accuracy and less mechanical computations, we use the revisited JainKhare semi-empirical formalism [7],[15]-[20] to determine

\footnotetext{
Revised Manuscript Received on 14 August, 2019.

Ravinder Sharma, Research Scholar, Dept. of Chemistry, Baba Mast Nath University, Rohtak, Haryana, India.(Email: ravindersharma.bme@dcrustm.org)

S.P.Sharma, Professor \& Dean Faculty of Sciences, Dept. of Chemistry, Baba Mast Nath University, Rohtak, Haryana, India(Email:
} spsharmabmu@gmail.com) direct and dissociative ionization cross sections of the $\mathrm{O}_{2}$ molecule.

\section{THEORETICAL METHODOLOGY}

We developed the MATLAB programming codes to calculate the ionization cross sections of the $\mathrm{O}_{2}$ molecule for the given equations. This gives ionization cross section to the production of an ith type of cation of the molecule by an incident electron of energy ' $E$ ' solving the following equations:

$$
\begin{aligned}
Q_{i}(E)=\frac{4 \pi \mathrm{a}_{0}^{2} R}{E}[ & \frac{E}{E-I_{i}}\left(M_{i}^{2}-\frac{R}{E} S_{i}\right) \ln \left[1+C_{i}\left(E-I_{i}\right)\right] \\
& +\frac{R\left(E-I_{i}\right)}{E} S_{i} \\
& \times \int_{0}^{\left(E-I_{i}\right) / 2} \frac{1}{\varepsilon^{3}+\varepsilon_{0}^{3}}\left(\varepsilon-\frac{\varepsilon^{2}}{(E-\varepsilon)}\right. \\
& \left.\left.+\frac{\varepsilon^{3}}{(E-\varepsilon)^{2}}\right) d \varepsilon\right]
\end{aligned}
$$

(1)

$$
\begin{aligned}
& \text { Where } \\
& M_{i}^{2}=\int_{I_{i}}^{\left(E+I_{i}\right)} \frac{R}{w} \frac{d f_{i}(w, 0)}{d w} d w \\
& S_{i}=\int_{I i}^{\left(E+I_{i}\right)} \frac{d f_{i}(w, 0)}{d w} d w \\
& C_{i=} C_{T} \exp \left[n\left(\frac{\sum_{i>1} M_{i}^{2} \ln S_{i}}{\sum_{i>1} M_{i}^{2}}-\ln S_{i}\right)\right]
\end{aligned}
$$

Where, $\varepsilon_{0}, \varepsilon, S_{i}, C_{i}, I_{i}, W, a_{0}$, and $R$ are the mixing parameter, secondary electron energy, number of ionizable electrons, collision parameter, ionization potential, energy loss suffered by the incident electron, Bohr radius, and Rydberg energy, respectively [20]. And $d f_{i} / d w$ is an oscillator strength that is a key parameter to calculate the ionization cross section (ICS). The oscillator strength can be calculated theoretically if the experimental data is not available as it is directly proportional to the photoionization cross section [17]. We have used the experimental values of absolute dipole oscillator strengths for dissociative ionization of $\mathrm{O}_{2}$ derived by C.E. Brion using (e, e+ ion) spectroscopy [21]. But the partial oscillator strengths of $\mathrm{O}_{2}^{+}, \mathrm{O}^{+}$ions are available up to $75 \mathrm{eV}$. Thus, for $W>75 \mathrm{eV}$, we extrapolate the same data by the TRK sum rule, within $5-10 \%$ error bars [22]. The ionization potentials for of $\mathrm{O}_{2}{ }^{+}, \mathrm{O}^{+}$are taken 12.07 $\mathrm{eV}$ and $18.59 \mathrm{eV}$ respectively [12]. The values derived for the total collision parameter and mixing parameter are $\left(C_{T}=0.04714\right)$ and $\left(\varepsilon_{0}=50\right)$ respectively. Summation of partial ionization cross sections (PICS) over the system gives the total ionization cross sections (TICS) as: 


$$
Q_{i}^{t}(E)=\sum_{i} Q_{i}(E)
$$

We calculated the ICS by varying the secondary electron energy from 0 to $\left(E-\mathrm{I}_{\mathrm{i}}\right) / 2$ using equations (1) because the results are more accurate and precise at this energy. However, Satyendra Pal [17] varying this energy from 0 to $\left(\mathrm{E}-\mathrm{I}_{\mathrm{i}}\right)$ for partial differential cross sections. In partial ionization cross sections, if we varying secondary electron energy from 0 to $\left(E-\mathrm{I}_{\mathrm{i}}\right)$, then results at low incident energies are more as compared experimental and all other theoretical data.

\section{RESULTS AND DISCUSSION}

In this literature, we calculate the ionization cross sections of $\mathrm{O}_{2}$ by electron impact using Equations (1) to (5) with the help of MATLAB programming codes. The calculated results for partial and total ionization cross sections are tabulated in Table 1and the partial ionization cross sections graphically presented inFig. I.We compare our results for the total ionization cross sections with some easily available theoretical and/or experimental data [1],[4],[6],[7], [12],[13] shown in Fig. II. All these give excellent agreement from threshold up to high energies. Here, the total ionization cross sections data are collected as the mentioned referred journals. But the TICS data of S.P. Khare [7] and Stefan E.Huber et al. [12] is extracted from the graphs with some error bars.

Table 1

Present Result for Dissociative Ionization cross-section of $\mathrm{O}_{2}$ molecule $\left(10^{-16} \mathrm{~cm}^{2}\right)$

\begin{tabular}{|c|c|c|c|c|c|c|c|}
\hline \multirow[t]{2}{*}{ Energy $(\mathrm{eV})$} & \multicolumn{2}{|c|}{ Fragmented ions } & \multirow[t]{2}{*}{ Total } & \multirow[t]{2}{*}{ Energy (eV) } & \multicolumn{2}{|c|}{ Fragmented ions } & \multirow[t]{2}{*}{ Total } \\
\hline & $\mathrm{O}_{2}^{+}$ & $\mathrm{O}^{+}$ & & & $\mathrm{O}_{2}^{+}$ & $\mathrm{O}^{+}$ & \\
\hline 25 & 0.2929 & 0.0654 & 0.3583 & 500 & 0.9955 & 0.3980 & 1.3935 \\
\hline 30 & 0.7127 & 0.0224 & 0.7351 & 550 & 0.9347 & 0.3728 & 1.3076 \\
\hline 35 & 1.0232 & 0.0457 & 1.0689 & 600 & 0.8815 & 0.3509 & 1.2323 \\
\hline 40 & 1.2561 & 0.2269 & 1.4831 & 650 & 0.8344 & 0.3314 & 1.1658 \\
\hline 45 & 1.4326 & 0.3535 & 1.7860 & 700 & 0.7924 & 0.3142 & 1.1066 \\
\hline 50 & 1.5666 & 0.4434 & 2.0100 & 750 & 0.7548 & 0.2987 & 1.0535 \\
\hline 55 & 1.6683 & 0.5106 & 2.1789 & 800 & 0.7209 & 0.2848 & 1.0057 \\
\hline 60 & 1.7455 & 0.5580 & 2.3035 & 850 & 0.6901 & 0.2722 & 0.9623 \\
\hline 65 & 1.8040 & 0.5921 & 2.3961 & 900 & 0.6621 & 0.2607 & 0.9228 \\
\hline 70 & 1.8479 & 0.6193 & 2.4673 & 950 & 0.6364 & 0.2503 & 0.8867 \\
\hline 75 & 1.8806 & 0.6418 & 2.5224 & 1000 & 0.6129 & 0.2407 & 0.8535 \\
\hline 80 & 1.9046 & 0.6604 & 2.5650 & 1100 & 0.5710 & 0.2236 & 0.7946 \\
\hline 85 & 1.9217 & 0.6849 & 2.6066 & 1200 & 0.5349 & 0.2090 & 0.7438 \\
\hline 90 & 1.9329 & 0.7072 & 2.6401 & 1300 & 0.5034 & 0.1962 & 0.6996 \\
\hline 95 & 1.9379 & 0.7185 & 2.6564 & 1400 & 0.4757 & 0.1851 & 0.6608 \\
\hline 100 & 1.9387 & 0.7295 & 2.6682 & 1500 & 0.4511 & 0.1752 & 0.6263 \\
\hline 110 & 1.9294 & 0.7396 & 2.6690 & 1600 & 0.4292 & 0.1664 & 0.5955 \\
\hline 120 & 1.9102 & 0.7418 & 2.6520 & 1700 & 0.4094 & 0.1584 & 0.5678 \\
\hline 130 & 1.8845 & 0.7387 & 2.6232 & 1800 & 0.3915 & 0.1513 & 0.5428 \\
\hline 140 & 1.8546 & 0.7320 & 2.5866 & 1900 & 0.3752 & 0.1448 & 0.5200 \\
\hline 150 & 1.8221 & 0.7229 & 2.5451 & 2000 & 0.3604 & 0.1389 & 0.4992 \\
\hline 160 & 1.7881 & 0.7123 & 2.5004 & 2100 & 0.3467 & 0.1334 & 0.4802 \\
\hline 170 & 1.7533 & 0.7006 & 2.4539 & 2200 & 0.3342 & 0.1284 & 0.4626 \\
\hline 180 & 1.7184 & 0.6883 & 2.4067 & 2300 & 0.3226 & 0.1238 & 0.4464 \\
\hline 190 & 1.6837 & 0.6756 & 2.3593 & 2400 & 0.3118 & 0.1196 & 0.4313 \\
\hline 200 & 1.6493 & 0.6629 & 2.3121 & 2500 & 0.3018 & 0.1156 & 0.4174 \\
\hline 210 & 1.6158 & 0.6501 & 2.2659 & 3000 & 0.2605 & 0.0993 & 0.3599 \\
\hline 220 & 1.5829 & 0.6374 & 2.2203 & 4000 & 0.2060 & 0.0780 & 0.2840 \\
\hline 230 & 1.5512 & 0.6250 & 2.1762 & 5000 & 0.1713 & 0.0645 & 0.2358 \\
\hline 240 & 1.5202 & 0.6128 & 2.1330 & 6000 & 0.1471 & 0.0552 & 0.2023 \\
\hline 250 & 1.4904 & 0.6009 & 2.0913 & 7000 & 0.1293 & 0.0483 & 0.1776 \\
\hline 300 & 1.3554 & 0.5463 & 1.9016 & 8000 & 0.1155 & 0.0431 & 0.1586 \\
\hline 350 & 1.2422 & 0.4999 & 1.7420 & 9000 & 0.1045 & 0.0389 & 0.1434 \\
\hline 400 & 1.1467 & 0.4605 & 1.6071 & 10000 & 0.0956 & 0.0355 & 0.1311 \\
\hline 450 & 1.0654 & 0.4269 & 1.4923 & - & - & - & - \\
\hline
\end{tabular}




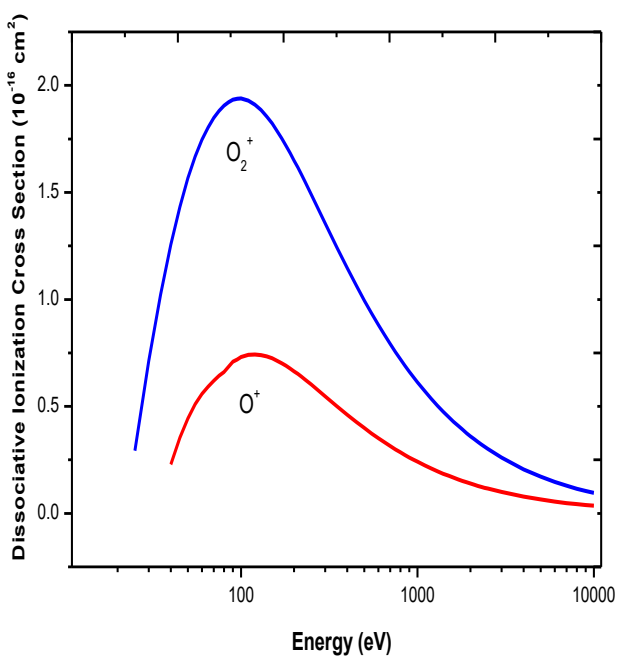

Fig. I: $\mathrm{O}_{2}$ Dissociative Partial Ionization Cross Section

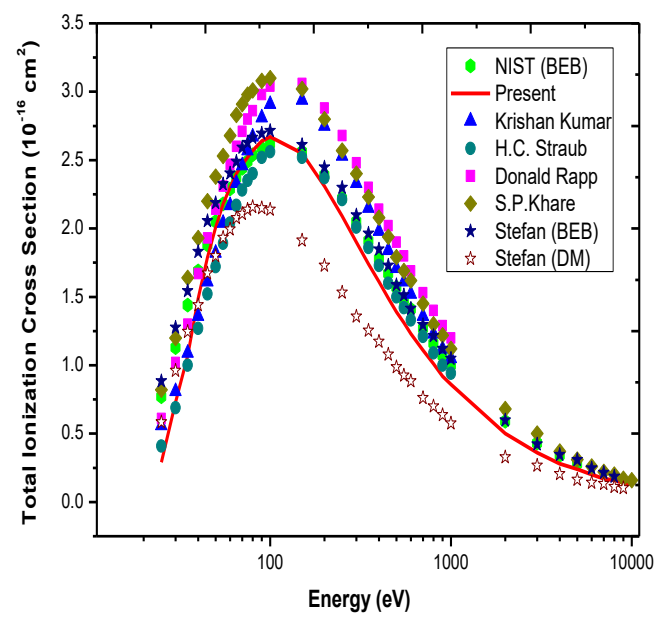

Fig. II: $\mathrm{O}_{2}$ TICS in $\AA^{2}$. Solid line, Present result; Pentagon, NIST [13].; Triangle, Krishan Kumar[4]; Circle, H.C.Straub [6]; Square, Donald Rapp[1]; Rectangle, S. P.Khare [7]; Solid star, Stefan (BEB) and star, Stefan (DM) [12].

\section{Direct Ionization Cross Sections:}

There are many channels for ionization of atoms/molecules. Here, the electron impact ionization technique is used for dissociation of $\mathrm{O}_{2}$ molecule as the mechanism for direct ionization of $\mathrm{O}_{2}$ molecule is given below:

$$
\mathrm{O}_{2}+\mathrm{e}^{-} \rightarrow \mathrm{O}_{2}^{+}+2 \mathrm{e}^{-}
$$

The calculated direct ionization cross section is also compared to the experimental data [2]-[3] shown in Fig.III. This also gives good agreement. There is double ionization for further fragmentation of $\mathrm{O}_{2}$ molecule as given in detail [4], [6].

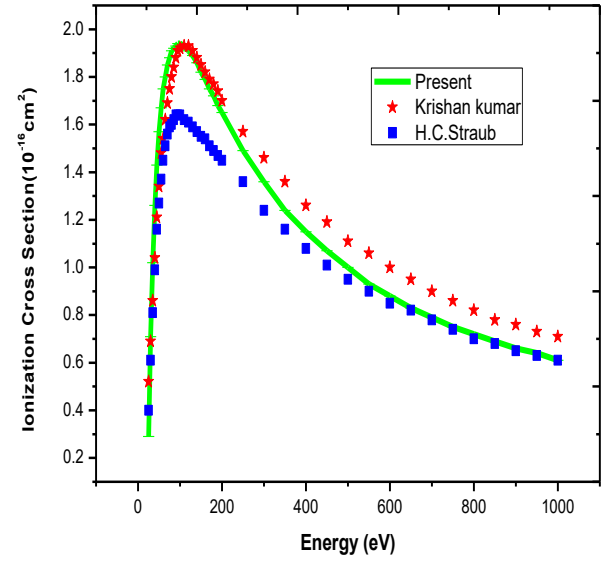

Fig.III: $\mathrm{O}_{2}$ Direct Ionization Cross Section $\left(\mathrm{O}_{2}^{+}\right)$. Solid line, Present result; Star, Krishan Kumar [4]; Square, H. C. Straub [6];

\section{CONCLUSION}

We calculate absolute partial and total ICS for $\mathrm{O}_{2}$ molecule and the results are also compared with theoretical and experimental available data from threshold energy to high energies. These comparisons have a very good agreement with H.C. Straub [6], Stefan E.Huber et al. (BEB) [12] and NIST (BEB). But there are some higher Peak values of cross sections of Donald Rapp [1], Krishan Kumar [4] and S.P.Khare [7] while Stefan E.Huber et al. (DM) [12] have low peak values. Thus, from the compared data and graphs, we can say that the developed programming can produce reliable cross sections even for complex molecules also. And the present data could be used in the plasma process, modeling systems, and other applications.

\section{REFERENCES}

1. D. Rapp and P. Englander-Golden, "Total cross sections for ionization and attachment in gases by electron impact. I. Positive Ionization,” The J. Chem. Phys., vol. 43, no. 5, pp. 1464-1479, 1965.

2. K. N. Joshipura, B. K. Antony, and V. Minaxi, "Electron impact cross sections with $\mathrm{O}$ atoms; $\mathrm{O} 2$ and $\mathrm{O} 3$ molecules - a theoretical survey," pp. 223-228, 2002.

3. J. A. R. Samson, G. H. Rayborn, and P. N. Pareek, "Dissociative photoionization cross sections of $\mathrm{O} 2$ from threshold to $120 \AA$," J. Chem. Phys., vol. 76, no. 1, pp. 393-397, 1982.

4. E. Krishnakumar and S.K.Srivastava, "Cross-sections for electron impact ionization of O2," Int. J. Mass Spectrom. Ion Process., vol. 113, pp.1-12 1992.

5. B.Van Zyl and T.M. Stephen. "Dissociative ionization $\mathrm{H} 2$, N2, and $\mathrm{O} 2$ by electron impact". The Journal of Physical Review A, 50(4),3164-3173, 1994.

6. H. C. Straub, P. Renault, B. G. Lindsay, K. A. Smith, and R. F. Stebbings, "Absolute partial cross sections for electron-impact ionization" Physical Review A, 54(3), 2146-2153, 1996.

7. S. P. Khare and B. D. Padalia "Total ionization cross sections of $\mathrm{He}, \mathrm{N} 2, \mathrm{H} 2$ and $\mathrm{O} 2$ due to electron impact". J. Phys. B At. Mol. Phys., vol. 3, pp.1073-1082,1970. 
8. D. Margreiter, H. Deutsch, M. Schmidt, and T. D. Mark, "Electron impact ionization cross sections of molecules," Int. J. Mass Spectrom. Ion Process., vol. 100, pp. 157$176,1990$.

9. H. Deutsch, K. Becker, S. Matt, and T. D. Märk, "Theoretical determination of absolute electron-impact ionization cross sections of molecules," Int. J. Mass Spectrom., vol. 197, no. 1-3, pp. 37-69, 2000.

10. A. Jain, K.L.Baluja, "Total (elastic plus inelastic) crosssections for electron scattering from diatomic and polyatomic molecules at $10-5000 \mathrm{eV}$. The Journal of Physical Review A, 45(1),202-218, 1991

11. Vandana Saksena, M.S Kushwaha. and S.P. Khare. "Ionization cross sections of molecules due to electron impact". The Journal of Physics B, 233,pp.201-212, 1997.

12. Stefan E. Huber et al, "Total and partial electron impact ionization cross sections of fusion-relevant diatomic molecules," J. Chem. Phys. 150, 024306, 2019.

13. https://physics.nist.gov/cgibin/Ionization/table.pl?ionization=O2.

R. Sharma, S. P. Sharma, and N. Kumari, "Electron Impact Ionization Cross Section Semi-empirical approach.” Pure Appl. Sci., vol. 36, no. 2, pp. 45-53, 2017.

14. R. Kumar and S. Pal, "Evaluation of electron ionization cross-sections of methyl halides," Rapid Commun. Mass Spectrom., vol. 27, no. 1, pp. 223-237, 2013.

15. R. Kumar, S. Kumar, S. Singh, and A. Chetan, "Single and double differential cross sections of PF3 molecule theoretical" pp. 123-126, 2016.

16. S. Pal, J. Kumar, and P. Bhatt, "Electron impact ionization cross-sections for the N2 and $\mathrm{O} 2$ molecules," J. Electron Spectros. Relat. Phenomena, vol. 129, no. 1, pp. 35-41, 2003.

17. S. Pal, M.Kumar, R. Singh, and N. Kumar, "Evaluation of electron-impact ionization cross sections for molecules," J. Phys. Chem. A vol. 123, pp. 4314-4321, 2019.

18. S. P. Khare and W. J. Meath, "Cross sections for the direct and dissociative ionization of $\mathrm{NH} 3, \mathrm{H} 2 \mathrm{O}$, and $\mathrm{H} 2 \mathrm{~S}$ by electron impact," J. Phys. B At. Mol. Phys., vol. 20, no. 9, pp. 2101-2116, 1987.

19. S. Pal, N. Kumar, and Anshu, "Electron-collisioninduced dissociative ionization cross sections for silane," Adv. Phys. Chem., vol. 2009, 2009.

20. C. E. Brion, and K.H. Tan; M. J.Van der Wiel \& P. E. Van der Leeuw "Dipole oscillator strengths for the photoabsorption, photoionization, and fragmentation of molecular oxygen," Journal of Electron Spectroscopy and Related Phenomena, vol. 17(2), pp. 101-119, 1979

21. G. D. Zeiss, J. M. William, J. C. F. MacDonald, and D. J. Dawson, "Dipole oscillator strength distributions, sums, and some related properties for $\mathrm{Li}, \mathrm{N}, \mathrm{H} 2, \mathrm{~N} 2, \mathrm{O} 2, \mathrm{NH} 3$, H2O, NO, and N2O," Canc. J. Phys., vol. 55, no. 23, pp. 2080-2100, 1977. 